\title{
Preparation of Activated Carbon from Acacia (Vachellia seyal) Tree Branches and Application to Treat Wastewater Containing Methylene Blue Dye
}

\author{
Muhammad Saleem ${ }^{1}$, Mehmood Ali $^{3}$, Zia Siddiqi ${ }^{2} \&$ Abdulrahman Saud Al Qahtani ${ }^{1}$ \\ ${ }^{1}$ Department of Civil Engineering, Jubail University College, Jubail Industrial City, Saudi Arabia \\ ${ }^{2}$ General Studies Department, Jubail University College, Jubail Industrial City, Saudi Arabia \\ ${ }^{3}$ Department of Environmental Engineering, NED University of Engineering \& Technology, Karachi, Pakistan \\ Correspondence: Muhammad Saleem, Department of Civil Engineering, Jubail University College, Jubail \\ Industrial City 31961, Saudi Arabia. Tel: 966-13-342-1342. E-mail: saleemm@ucj.edu.sa
}

Received: February 22, 2017

Accepted: March 8, 2017 Online Published: November 27, 2017

doi:10.5539/mas.v11n12p102

URL: https://doi.org/10.5539/mas.v11n12p102

\begin{abstract}
Saudi Arabian desert tree Acacia (Vachellia Seyal) used to produce Activated Carbon (AC) by phosphoric acid mediated chemical activation at low temperature. Characterization of $\mathrm{AC}$ done based on proximate and detailed analysis including Moisture content, Total Ash content, $\mathrm{pH}$ value, Iodine number, Methylene blue number, pore volume and BET surface area. Results revealed that properties of produced activated carbon (PAC) are comparable to commercial activated carbon (CAC). Low ash content and hardness making it suitable for water and wastewater treatment. Cost of production found to be less than $\$ 0.5 / \mathrm{kg}$. Both AC used to treat wastewater containing Methylene Blue (MB) dye. Initially the removal efficiency of CAC is higher than the PAC however, both $\mathrm{AC}$ reached to similar removal (95.3\% for PAC and $98.2 \%$ for CAC) within one hour. Growing demand of $\mathrm{AC}$ in the country can be meet by producing low cost locally available waste materials Acacia seyal tree branches.
\end{abstract}

Keywords: activated carbon, acacia seyal, phosphoric acid activation, removal efficiency, MB dye uptake capacity

\section{Introduction}

Due to high degree of porosity, typically one gram of activated carbon (AC) has a surface area in access of 500 $\mathrm{m}^{2}$ (Yang et al., 2010). Some researchers also reported the BET surface area from 1494 to $1581 \mathrm{~m}^{2} / \mathrm{g}$ which makes it a favorite candidate as an adsorbent (Ahmed et al., 2015). Recently some researchers achieved surface area up to $2939 \mathrm{~m}^{2} / \mathrm{g}$ by additional activation with potassium hydroxide (Buczek, 2016).

At present $\mathrm{AC}$ is the most extensively used adsorbent in the industries as well as for domestic applications capable of treating diverse type of effluents (Joshi, 2016). Saudi Arabia is one of the countries having wide range industrial setup and AC is being used in various industries such as power, chemical, paper, pharmaceutical, fertilizer, and textile industries. In order to meet the country's demand a substantial amount of foreign exchange spent to import AC. It is reported that during year 1995 to year 2002 about 6507 tons of AC was imported into the Kingdom and spent more than \$23.1 million as foreign exchange (Essa et al., 2004). The high cost of AC has stimulating effect in assessing the feasibility of using cheaper raw materials. In order to cope with the huge requirement, AC should be prepared using locally available raw materials and cost effective production technique. Use of waste material could be an additional benefit (Rehman, 2008). Desert plant Acacia considered as a waste material and available abundantly in many regions of country (Aref et al., 2003). Production of AC from this material seems to be financially more viable since using grain or coal as raw materials for AC will require manufacturers extra amount of money for procurement. Furthermore, carbon produced from this tree is harder and more resistant to attrition (Gratuito et al., 2008). Although there are many studies in the literature relating the preparation and characterization of $\mathrm{AC}$ from carbonaceous materials however, there is limited information for the preparation of the $\mathrm{AC}$ using Acacia seyal tree branches as the precursor material. The conversion of Acacia seyal tree branches to ACs offers significant potentials for reducing the cost and the environmental damage resulting from decay and disposal of these residues (Shivayogimath et al., 2014). 
AC can be produce by physical activation and/or chemical activation. Physical activation is a two steps method in which a raw material is first carbonized and then activated by steam, carbon dioxide, air or their mixtures. The carbonization temperature range between 400 and $1000^{\circ} \mathrm{C}$; and activation temperature range between 600 and $900^{\circ} \mathrm{C}$ (Shoaib and Al-Swaidan, 2016). In the chemical activation the carbonization and activation steps are carried out simultaneously. A raw material is impregnated with a chemical activating agent and heat-treated under inert atmosphere (Li et al., 2016). Phosphoric acid activation of lignocellulosic materials has become an increasingly used method for the large-scale manufacture of ACs in the last 20 years because phosphoric acid activation has environmental benefits and several other advantages, such as ease of recovery as compared to zinc chloride activation, low energy cost, and high char yield (Lim et al., 2010). Thus, investigations have been extensively conducted to elucidate the mechanism of phosphoric acid activation (Olawale at al., 2016; Zuo et al., 2009). Since the surface characteristic and internal pore structure of the AC play an important role in adsorption processes and depend both on the precursor used and the method of preparation, therefore, characterization of these are crucial to the adsorption and separation processes (Anisuzzaman et al., 2015).

\section{Materials and Method}

In the present study after selection of precursor material Acacia seyal tree branches detailed experimental work performed to 1) produce $\mathrm{AC}$ using phosphoric acid mediated chemical activation, 2) characterize the produced $\mathrm{AC}$ and 3) find adsorption capacity of PAC and compare with the available CAC (Filtrasorb ${ }^{\circledR}-400$ ) obtained from Calgon Carbon Corporation, Pennsylvania, 15205 USA.

\subsection{Production of Activated Carbon}

Acacia seyal tree branches were collected from costal area of Jubail Industrial city. Material was thoroughly washed with hot distilled water to remove impurities and dried in an oven at $120 \pm 5{ }^{\circ} \mathrm{C}$ for 24 hours. Dried pieces were than chopped in pieces using a chopper/cutting mill. The final particle size of the material achieved was 0.4 to $0.5 \mathrm{~mm}$.

Chemical activation with phosphoric acid was used to produce AC as it is relatively easy and does not require skilled and trained personnel. Method requires less heat and it has less complex operating conditions as compared to physical or steam activation techniques and a simple laboratory set up is sufficient. One kilogram of the prepared precursor material was mixed with $40 \% \mathrm{~V} / \mathrm{V}$ phosphoric acid having actual concentration of 85.5 wt\% (Rehman, 2008). A slurry was formed which was left overnight in the oven at $120 \pm 5{ }^{\circ} \mathrm{C}$. After 24 hours slurry was transferred into specially fabricated stainless steel hollow cylinders having $50 \mathrm{~mm}$ dia and $140 \mathrm{~mm}$ length. Two narrow ports of $4 \mathrm{~mm}$ diameter (for flue gases exhaust) and two removable end caps were provided at both ends of each tube. After preparation cylinders were placed inside a muffle furnace and were heated at a slow rate, to allow free evolution of volatiles up to a hold temperature of $600^{\circ} \mathrm{C}$. Soaked material was kept at final temperature for 2 hours. Later cooled material was repeatedly washed with hot water until the washings showed $\mathrm{pH}>6.5$; the washed sample was then again dried at $120 \pm 5{ }^{\circ} \mathrm{C}$ for 2 hours and kept in air-tight bottles ready for characterization and use. The percentage yield of PAC was found to be $62.7 \%$.

\subsection{Characterization and Application of PAC to Remove MB Dye from Wastewater}

In order to characterize PAC as a first step elemental analysis of selected precursor material was done. Characterization of PAC was done on the basis of proximate and detailed analysis by adopting the standard procedures (Schaeffer, 2002). The specific surface area, pore volume, iodine number (ASTM D4607-94), bulk density (ASTM D2395), volatile matter content (ASTM D5832-98), moisture content (ASTM D4933-99, 2010), $\mathrm{pH}$ value (ASTM D3838-05), hardness (ASTM D3802, using Gilson SS-30 Ro-Tap Sieve Shaker), and ash content (ASTM D2866-94, 2004) were determined. Surface area of the AC was characterized by a physical technique involving nitrogen adsorption at $195.6^{\circ} \mathrm{C}$ (Brunauer-Emmett-Teller, BET surface area).The total pore volume was determined from the amount of liquid N2 held at $\mathrm{P} / \mathrm{Po}=0.98$. Freshly boiled water was digested with the dried carbon and the $\mathrm{pH}$ was determined for the clear solution using a $\mathrm{pH}$ meter. Bulk densities for the 0.4-0.5 mm particle size material were also determined. All the results of characterization analysis are discussed in the next section.

As methylene Blue (MB) dye is one of the common dye in the textile effluent removal of MB dye from synthetic wastewater was tested by using PAC (Shah et al., 2016; Li et al., 2016). During adsorption study stock solution of MB by dissolving $100 \mathrm{mg}$ in one liter of distilled water was prepared and consequently various dilutions were prepared according to need.

The efficiency of MB dye (E) removal from synthetic wastewater was investigated using following relationship (Kamil et al., 2014). 


$$
E=\left(C_{0}-C_{f}\right) / C_{0} \times 100
$$

Where, $C_{0}$ is the initial concentration of $\mathrm{MB}$ dye and $C_{f}$ is the concentration of MB dye in aqueous phase by the end of study time. Same procedure was repeated with the CAC (Filtrasorb $\left.{ }^{\circledR}-400\right)$ to make comparative study.

\subsection{Adsorption Capacity of the PAC}

In order to check the adsorption capacity of PAC and simulate treatment of textile wastewater synthetic textile wastewater containing Methylene Blue (MB) dye was used. A stock solution of MB (40 mg/l) was prepared and dispensed in two sets of 100-ml bottles. Each bottle containing $5 \mathrm{gm}$ of respective AC (PAC and CAC). These stoppered bottles were placed in a mechanical shaker and left to equilibrate for a period of 48 hours. At the end of equilibration period mixture was centrifuges three times to separate the small AC particles. Samples were withdrawn from each bottle, filtered through $0.45 \mu \mathrm{m}$ filter (Millipore), and analyzed for the MB residual concentrations using the UV-spectrophotometer, Shimadzu UV-160IPC at a wavelength of $664 \mathrm{~nm}$. A calibration curve (Absorbance vs concentration) was prepared by using standard MB solutions between 10 to $50 \mathrm{mg} / \mathrm{l}$. In order to compare the adsorption capacity of PAC samples of CAC (Filtrasorb ${ }^{\circledR}-400$ ) was also used in parallel and adsorption capacity of both $\mathrm{AC}$ was determined.

\section{Results and Discussion}

Details of the results obtained in the present study along with discussion on results presented in the following sections.

\subsection{Production of Activated Carbon}

Generally, to prepare a good quality AC the precursor materials selected as it has higher carbon content with low sulfur and ash content (Sánchez-Polo et al., 2006). A comparison of elemental analysis results of Acacia seyal tree branches with values reported in the literature is presented in table 1. Result shows that Acacia seyal tree wood has higher carbon content which is a favorable component to produce good quality AC (Shivayogimath et al., 2014). Other elements such as nitrogen, hydrogen and oxygen are similar to the composition of Acacia nilotica and pine bark reported in literature for production of AC. Furthermore, sulfur content is only $0.03 \%$ which is making this precursor material more environmental friendly to use (Shahid, 2011). Hence, results shows that Acacia seyal tree branches are suitable precursor material to produce good quality AC.

Table 1. Comparison of elemental analysis results of precursor Acacia seyal tree branches with values reported in literature

\begin{tabular}{lllll}
\hline Constituent (\%) & Acacia seyal & ${ }^{1}$ Shisham wood & ${ }^{2}$ Acacia nilotica & ${ }^{3}$ Pine Bark \\
\hline $\mathrm{C}$ & 51.3 & 41.2 & 48 & 54.9 \\
$\mathrm{~K}$ & 1.82 & 1.2 & -- & -- \\
$\mathrm{Al}$ & 0.17 & 0.2 & -- & -- \\
$\mathrm{N}$ & 0.33 & -- & 0.4 & 0.2 \\
$\mathrm{H}$ & 5.8 & -- & 6 & 5.8 \\
$\mathrm{Zn}$ & 0.01 & $\mathrm{ND}$ & -- & -- \\
$\mathrm{S}$ & 0.03 & 0.04 & -- & 0.1 \\
$\mathrm{P}$ & 0.09 & 5.4 & -- & -- \\
$\mathrm{O}$ & 32.9 & 39.7 & 44 & 39.0 \\
Ash & 5.9 & 4.9 & 5.8 & -- \\
\hline
\end{tabular}

ND: Not Detected

\footnotetext{
${ }^{1}$ Shahid (2011)

${ }^{2}$ Shivayogimath et al., (2014)

${ }^{3}$ Ragland et al., (1991); Saarela et al., (2005
}

Some of the properties/characteristics of PAC with the properties of two commercially available AC (Filtrasorb ( -400 and QAC-400) and information available in literature (Shisham wood and Acacia nilotica) are presented in table 2. Results show that PAC has a comparable BET-surface area. Higher the surface area means more sites are available for adsorption and AC will has higher adsorption capacity (Buczek, 2006). BET-surface area obtained is about $80.7 \%$ of CAC (Filtrasorb ${ }^{\circledR}-400$ ) and higher than all other AC reported here. Similar trend was found in iodine number $(82.7 \%)$. It shows that produced $\mathrm{AC}$ is a feasible adsorbent while considering the 
availability of raw material and cost. The value of pore volume and iodine number $\left(4.92 \mathrm{~m}^{3} / \mathrm{g}\right.$ and 827$)$ are in good agreement with values reported in literature and commercially available ACs. Furthermore, produced AC has relatively higher hardness and making it suitable for continues flow type setups. In addition to that, the low ash content of the produced AC (5.9\%) is making it suitable in mixed flow/batch type of reactors. A basic cost analysis including material acquisition, chemical, labor and lab analysis cost was performed. It was found that the cost of AC produced from Acacia seyal tree branches is less than $\$ 0.5 / \mathrm{kg}$. As low cost waste material will be used for $\mathrm{AC}$ production this strategy will results in economic production of $\mathrm{AC}$ and reduction in solid waste in the country.

Table 2. Comparison for the characteristics of PAC and CAC

\begin{tabular}{|c|c|c|c|c|c|}
\hline Property & Acacia seyal & ${ }^{1}$ Shisham wood & ${ }^{2}$ Acacia nilotica & ${ }^{*}$ Filtrasorb $₫ 400$ & ${ }^{\#} \mathrm{QAC}-400$ \\
\hline Ball Point Hardness & 91 & Low & Low & High & 95 \\
\hline Ash (\%) & 5.9 & 4.9 & 5.8 & $5-6$ & 6 \\
\hline Bulk Density (g/cc) & 0.3 & 0.23 & -- & 0.44 & 0.55 \\
\hline Moisture Content (\%) & 4.2 & -- & 4.1 & -- & 5 \\
\hline $\mathrm{pH}$ & 6.5 & 5.7 & 7.0 & 6.2 & $9-10$ \\
\hline BET-Surface Area $\left(\mathrm{m}^{2} / \mathrm{g}\right)$ & 762 & 695 & 590 & 944 & 400 \\
\hline Pore Volume $\left(\mathrm{m}^{3} / \mathrm{g}\right)$ & 4.92 & 5.17 & 4.4 & 0.6 & -- \\
\hline Iodine Number & 827 & 813 & 480 & 1000 & 400 \\
\hline
\end{tabular}

* Calgon Carbon Corporation, Pennsylvania, 15205 USA.

\# Quantum Active Carbon Pvt Limited (2016)

${ }^{1}$ Shahid (2011)

${ }^{2}$ Shivayogimath et al., (2014)

\subsection{Removal Efficiency of PAC}

Removal efficiency of PAC along with CAC (Filtrasorb $\left.{ }^{\circledR}-400\right)$ was determined by suspension of both AC in $100 \mathrm{ml}$ of $\mathrm{MB}$ solution having concentration of $40 \mathrm{mg} / \mathrm{l}$.

The removal efficiency of PAC and CAC with time is shown in figure 1which shows that the removal efficiency of $\mathrm{AC}$ can be divided in three zones initially the rate of $\mathrm{MB}$ dye removal is high and in second zone rate of removal is relatively low which is following by equilibrium zone showing insignificant removal. By comparing PAC with CAC, initially the uptake of CAC is higher than the PAC however, both AC reached to similar removal (95.3\% for PAC and 98.2\% for CAC). The impregnation of phosphoric acid before carbonization showed a good effect on the precursor material on BET surface area and porosity development which produced AC of good removal efficiency $(95.3 \%)$.

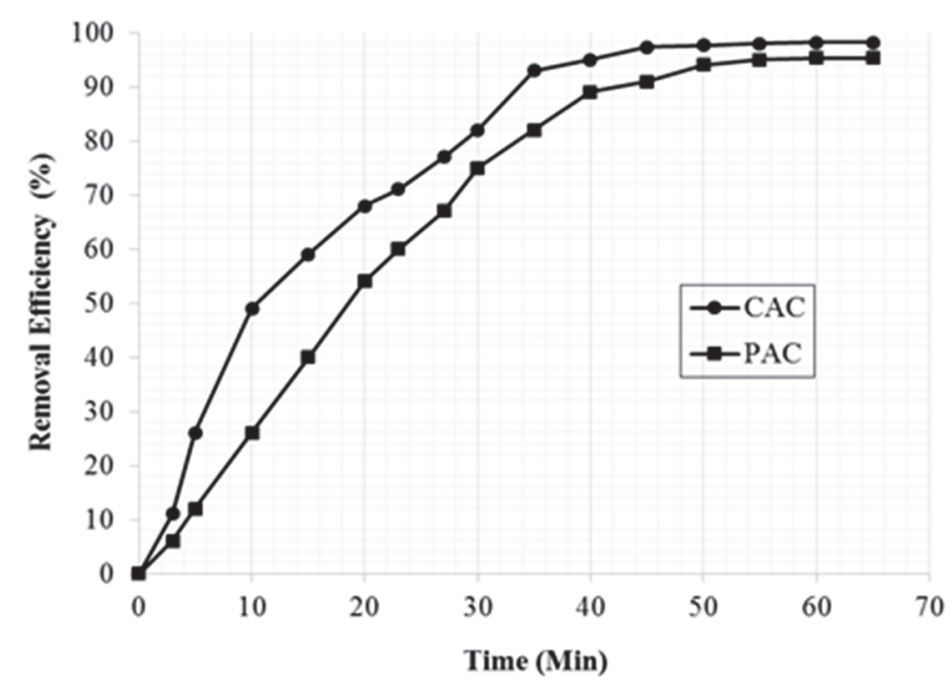

Figure 1. Comparison of removal efficiency of PAC and CAC for MB dye removal 


\subsection{MB Dye Uptake Capacity of PAC}

MB dye uptake capacity of PAC and CAC was studied by following the adsorption of MB from aqueous solution. Study shows that the MB uptake capacity for PAC and CAC are $194.3 \mathrm{mg} / \mathrm{g}$ and $241.3 \mathrm{mg} / \mathrm{g}$ respectively.

It means that the adsorption capacity of PAC is about $80.52 \%$ of CAC. This value is comparable to the BET-Surface area value which is about $80.7 \%$ of CAC. This shows a relationship between BET-Surface area and the adsorption capacity of AC. Furthermore, the pore volume of PAC is $4.92 \mathrm{~m}^{3} / \mathrm{g}$ while for CAC (Filtrasorb (B-400) is only $0.6 \mathrm{~m}^{3} / \mathrm{g}$ which means that the adsorption capacity is not only controlled by pore volume and dominating factor for PAC is BET-Surface area. This result is in contrast of Hussein et al., findings which is reporting the dependency of adsorption capacity mainly on the pore structure and volume (Hussein et al., 2015). This difference may be attributed to the difference in the precursor material as they used date palm in their study and $\mathrm{AC}$ from date palm may has dependency on pore volume due to different pore structure of said material (Saleem et al., 2010).

These differences in behavior necessitate the further investigation of various precursor materials for their adsorption capacities to relate them with their pore structure, pore volume and BET-Surface area.

\section{Conclusions}

Desert tree Acacia seyal is abundant in Saudi Arabia and tree branches are common waste material to dispose in environment friendly manner. It has potential as a precursor material to be used for the production of AC by means of chemical activation with phosphoric acid. PAC can be used to remove color dye (MB-dye) from wastewater. Following conclusions are drawn from the results of this study:

- The chemical activation of Acacia seyal tree branches with phosphoric acid showed that it could be a preferred method to produce low cost and good quality $\mathrm{AC}$ at low carbonization temperature of $600^{\circ} \mathrm{C}$ having adsorption capacity of $194.3 \mathrm{mg} / \mathrm{g}$.

- AC produced from tree branches has comparable surface area $\left(762 \mathrm{~m}^{2} / \mathrm{g}\right)$ which is about $80.7 \%$ of the CAC Filtrasorb ${ }^{\circledR}-400$.

- Removal efficiency of PAC with time was investigated and found that initially the uptake of CAC is higher than the PAC however, both AC reached to similar removal $(95.3 \%$ for PAC and $98.2 \%$ for $\mathrm{CAC}$ ).

- Low ash content and higher hardness making it suitable for mixed flow/batch type as well as for continues flow reactors in water and wastewater treatment.

- The basic cost analysis of the PAC shows that it is a low cost adsorbent and cost is less than $\$ 0.5 / \mathrm{kg}$ which is far cheaper than available costly commercial ACs.

- Growing demand of AC in the country can be meet by producing low cost locally available waste materials such as Acacia seyal tree branches. This strategy will not only provide the low cost AC but also help in reducing worth less solid waste.

\section{Acknowledgments}

Authors are grateful to the JUC to provide support and facility to conduct this research and KFUPM for providing technical help and support. This research did not receive any specific grant from any funding body.

\section{References}

Ahmad, A., Al-Swaidan, H. M., \& Alghamdi, A. H., (2015). Production of Activated Carbon from Raw Date Palm Fronds by ZnCl2 Activation. Journal of the Chemical Society of Pakistan, 37(6), 1081-1087. Retrieved Februry, 2017, from http://jcsp.org.pk/PublishedVersion/da1050bc-8125-4cdc-ac13-985f52ab3159Manuscript \%20no\%202,\%20 Final\%20Gally\%20Proof\%20of\%2010561\%20(Hassan\%20Mohammed\%20Al-Swaidan).pdf

Anisuzzaman, S. M., Joseph, C. G., Daud, W. M. A. B. W., Krishnaiah, D., \& Yee, H. S. (2015). Preparation and characterization of activated carbon from Typha orientalis leaves. International Journal of Industrial Chemistry, 6(1), 9-21. https://doi.org/10.1007/s40090-014-0027-3

Aref, I. M., Elkhalifa, K. F., \& El-Juhany, L. I. (2003). A dendrological key for identification of Acacia species growing in Saudi Arabia and Northern Sudan. https://doi.org/10.1.1.611.2817

Buczek, B. (2016). Preparation of Active Carbon by Additional Activation with Potassium Hydroxide and Characterization of Their Properties. Advances in Materials Science and Engineering, 2016. 
https://doi.org/10.1155/2016/5819208. Accessed on July, 2016

Essa, M. H., Al-Zahrani, M. A., \& Nesaratnam, S. (2004). A step towards national reliance using locally produced activated carbon from dates. In Third Saudi Technical Conference and Exhibition (STCEX-3), Riyadh, Saudi Arabia (pp. 291-297). Retrieved January, 2017, from https://www.researchgate.net/profile/Muhammad_Al-Zahrani3/publication/268272667_A_Step_Towards_N ational_Reliance_Using_Locally_Produced_Activated_Carbon_from_Dates/links/54bcd01 0 c0cf24e50e9409 416.pdf

Gratuito, M. K. B., Panyathanmaporn, T., Chumnanklang, R. A., Sirinuntawittaya, N. B., \& Dutta, A. (2008). Production of activated carbon from coconut shell: optimization using response surface methodology. Bioresource Technology, 99(11), 4887-4895. https://doi.org/10.1016/j.biortech.2007.09.042

Hussein, F. H., Halbus, A. F., Lafta, A. J., \& Athab, Z. H. (2015). Preparation and Characterization of Activated Carbon from Iraqi Khestawy Date Palm. Journal of Chemistry, 2015. https://doi.org/10.1155/2015/295748. Accessed on July, 2016.

Joshi, R. R. (2016). Optimization of Conditions for the Preparation of Activated Carbon from Lapsi (Choerospondias axillaris) Seed Stone Using ZnCl2. Journal of the Institute of Engineering, 11(1), 128-139. https://doi.org/10.3126/jie.v11i1.14707

Kamil, A. M., Abdalrazak, F. H., Halbus, A. F., \& Hussein, F. H. (2014). Adsorption of bismarck brown R dye onto multiwall carbon nanotubes. Journal of Environmental Analytical Chemistry, 1(1), 1-104. https://doi.org/10.4172/2380-2391.1000104

Li, D., Yan, J., \& Liu, Z. (2016). Adsorption kinetic studies for removal of methylene blue using activated carbon prepared from sugar beet pulp. International Journal of Environmental Science and Technology, 13(7), 1815-1822. https://doi.org/10.1007/s13762-016-1012-5.

Lim, W. C., Srinivasakannan, C., \& Balasubramanian, N. (2010). Activation of palm shells by phosphoric acid impregnation for high yielding activated carbon. Journal of Analytical and Applied Pyrolysis, 88(2), 181-186. https://doi.org/10.1016/j.jaap.2010.04.004

Olawale, A. S., Ajayi, O. A., Olakunle, M. S., Ityokumbul, M. T., \& Adefila, S. S. (2015). Preparation of phosphoric acid activated carbons from Canarium Schweinfurthii Nutshell and its role in methylene blue adsorption. Journal of Chemical Engineering and Materials Science, 6(2), 9-14. https://doi.org/10.5897/JCEMS2015.0219.

Quantum Active Carbon Pvt Limited. (2016). Retrieved July, 2016, from http://www.indiamart.com/proddetail/granular-activated-carbon-1700550830.html

Ragland, K. W., Aerts, D. J., \& Baker, A. J., 1991. Properties of wood for combustion analysis. Bioresource technology, 37(2), 161-168. https://doi.org/10.1016/0960-8524(91)90205-X

Rehman, R. M. (2008). "Production and characterization of low cost activated carbon from locally available raw materials" (Unpublished master's thesis), KANUPP Institute of Nuclear Power Engineering, Karachi, Pakistan.

Saarela, K. E., Harju, L., Rajander, J., Lill, J. O., Heselius, S. J., Lindroos, A., \& Mattsson, K. (2005). Elemental analyses of pine bark and wood in an environmental study. Science of the Total Environment, 343(1), 231-241. https://doi.org/10.1016/j.scitotenv.2004.09.043

Saleem, M., Mohsin, F., \& Zaman, N. (2010). "Production, Characterization and Adsorption Isotherm Study for Activated Carbon Produced at KINPOE". 3rd National "Energy Resources of Pakistan: Potential, Utilization, Conservation and Impact on Environment" at Quaid-e-Awam University of Engineering, Science \& Technology, Nawabshah, March 18-20, 2010.

Sánchez-Polo, M., Salhi, E., Rivera-Utrilla, J., \& Von Gunten, U. (2006). Combination of ozone with activated carbon as an alternative to conventional advanced oxidation processes. Ozone: Science and Engineering, 28(4), 237-245. https://doi.org/10.1080/01919510600714170

Schaeffer, K. E. (2002). "ASTM International Activated Carbon Standards, stock Number ACTCARBON". ASTM Committee on Activated Carbon, D-28. 2002. https://doi.org/10.1520/D6851-02R11.

Shah, I., Adnan, R., Ngah, W. S. W., \& Mohamed, N. (2015). Iron Impregnated Activated Carbon as an Efficient Adsorbent for the Removal of Methylene Blue: Regeneration and Kinetics Studies. PloS One, 10(4), e0122603. https://doi.org/10.1371/journal.pone.0122603. Accessed on January, 2017. 
Shahid, M., Saleem, M., Ibrahim, F., 2011. Production and characterization of activated carbon using indigenous waste materials. Pakistan Journal of Scientific \& Industrial Research, 54(3), 152-154. Retrieved January, 2017, from http://www.pjsir.org/documents/journals/21102011055632_PJSIR54A(3)-Abstract.pdf

Shivayogimath, C. B., Hiremath, M.N. and Lokeshappa B. (2014). Preparation and Characterization of Granular Activated Carbon from Acacia Nilotica Stalk by KOH Activation. International Journal of Engineering Science and Innovative Technology, 3(6), 201-207. Retrieved February, 2017, from http://www.ijesit.com/Volume\%203/Issue\%206/IJESIT201406_27.pdf

Shoaib, M., \& Al-Swaidan, H. M. (2016). Optimization of activation temperature on the preparation of sliced porous activated carbon from date fronds by physical activation. Chemical Industry/Hemijska Industrija, 70(2), 151-157. https://doi.org/10.2298/HEMIND140916022S

Yang, K., Peng, J., Srinivasakannan, C., Zhang, L., Xia, H., \& Duan, X. (2010). Preparation of high surface area activated carbon from coconut shells using microwave heating. Bioresour Technol., 101(1), 6163-6169. https://doi.org/10.1016/j.biortech.2010.03.001

Zuo, S., Yang, J., Liu, J., \& Cai, X. (2009). Significance of the carbonization of volatile pyrolytic products on the properties of activated carbons from phosphoric acid activation of lignocellulosic material. Fuel Processing Technology, 90(7), 994-1001. https://doi.org/10.1016/j.fuproc.2009.04.003

\section{Copyrights}

Copyright for this article is retained by the author(s), with first publication rights granted to the journal.

This is an open-access article distributed under the terms and conditions of the Creative Commons Attribution license (http://creativecommons.org/licenses/by/4.0/). 